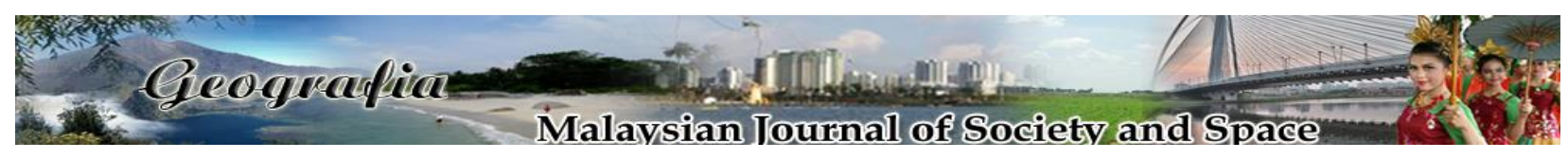

\title{
Budaya politik masyarakat Melayu: Satu analisis
}

\author{
Zawiyah Mohd Zain \\ Pusat Pengajian Kerajaan, Kolej Undang-Undang, Kerajaan dan Pengajian Antarabangsa, \\ Universiti Utara Malaysia
}

Correspondence: Zawiyah Mohd Zain (email: zmzain@uum.edu.my)

Received: 09 July 2020; Accepted: 05 January 2021; Published: 27 February 2021

\begin{abstract}
Abstrak
Budaya politik di Malaysia khususnya budaya politik orang Melayu adalah tidak menonjol yang mana mereka tidak akan menyatakan sesuatu pendirian kecuali dicabar seperti dalam peristiwa 13 Mei 1969. Terbaru pada Disember 2018, masyarakat Melayu bangkit melakukan demonstrasi secara besar-besaran menentang Konvensyen Antarabangsa Mengenai Penghapusan Segala Bentuk Diskriminasi Kaum (ICERD), iaitu ratifikasi antarabangsa Pertubuhan Bangsa-Bangsa Bersatu (PBB) yang menuntut mewujudkan kesaksamaan antara semua tanpa mengira kaum. Objektif kajian ini adalah bertujuan untuk menganalisis budaya politik masyarakat Melayu berdasarkan kepada konsep budaya politik melalui pendekatan "parochial", "subject" dan "participant". Kajian ini menggunakan kaedah kualitatif dengan menggunkan pendekatan analisis dokumen dan juga pemerhatian dengan mengambil kira isu-isu semasa yang berlaku dalam politik Malaysia. Hasil kajian menunjukkan budaya politik masyarakat Melayu telah mengalami satu tahap perubahan iaitu daripada budaya politik "subject" ke budaya politik "participant". Hal ini terbukti menerusi peristiwa politik yang berlaku sepanjang 20 tahun, bermula era reformasi sehingga ke era Malaysia baharu. Secara teorinya, kajian ini memberi sumbangan dalam bidang politik dengan memberikan gambaran tentang perubahan landskap politik dalam masyarakat Melayu sejak kemerdekaan sehingga ke hari ini. Manakala, secara praktikalnya, kajian ini amat penting ke arah keseimbangan dan kematangan proses demokrasi.
\end{abstract}

Kata Kunci: Budaya politik, demonstrasi, masyarakat Melayu, parti politik, pilihan raya, reformasi 


\title{
The Malay political culture: An analysis
}

\begin{abstract}
Malaysia political culture especially Malay political culture are not prominent, they tend to avoid and silence except for being challenged as it happened on May 13, 1969. Recently on December 2018, the Malay community rose to a massive demonstration against issues relating to the International Convention on the Elimination of All Forms of Racial Discrimination (ICERD), which the international ratification of the United Nations (UN) that seeks to create equality between all and regardless of race. The objective of this study is to analyse the political culture of Malay community base on political culture concept which is parochial, subject and participant. This study uses qualitative methods of document analysis, as well as observations taking into account current issues in Malaysian politics. The results showed the political culture of the Malay community has undergone a phase change, from subject political culture to the participant political culture. This is evidenced by the political events that have taken place over the past 20 years, beginning the era of reforms to the new era of Malaysia. Theoretically, this study contributed in politics by giving an overview of the changing political landscape in Malay society since independence to this day. Meanwhile, practically, this study is crucial towards the balance and maturity of the democratic process.
\end{abstract}

Keywords: Political culture, demonstrations, Malay community, political parties, elections, reforms

\section{Pengenalan}

Politik Malaysia adalah stabil yang mana ia dipengaruhi oleh budaya masyarakat. Tiga kaum utama di Malaysia, iaitu Melayu, Cina dan India banyak mempengaruhi pembentukan budaya politik di Malaysia terutama kaum Melayu. Politik Malaysia walaupun stabil, kadang-kala tegang disebabkan peristiwa tertentu. Misalnya, tragedi 13 Mei 1969 yang berlaku akibat pergaduhan antara kaum Melayu dan Cina. Ia berpunca daripada hasutan perkauman yang melampau semasa kempen politk dalam PRU 1969 dan juga semasa meraikan kemenangan selepas keputusan PRU 1969 diumumkan. Peristiwa tersebut telah menyebabkan huru-hara dan pertumpahan darah di sekitar Lembah Klang, sehingga akhirnya kerajaan telah mengisytiharkan darurat. Setelah Tun Razak mengambil alih pemerintahan negara, beliau memberi tumpuan kepada perpaduan nasional dan juga pembangunan ekonomi yang seimbang antara kaum di Malaysia. Sejak itu, keadaan sosial dan politik Malaysia kembali harmoni. Namun, di akhir pemerintahan Dr. Mahathir pada tahun 1998 politik Malaysia digegarkan dengan peristiwa pemecatan Timbalan Perdana Menteri Anwar Ibrahim. Hal ini telah menyebabkan kemarahan orang Melayu sehingga mengurangkan sokongan kepada kerajaan UMNO (Pertubuhan Kebangsaan Melayu Bersatu) / Barisan Nasional (BN) pada PRU 1999. Di era kepimpinan Abdullah Badawi dan seterusnya Najib Razak, kebangkitan orang Melayu berterusan disebabkan ketidakpuasan terhadap isu-isu tertentu dalam pentadbiran kerajaan.

Persoalannya, adakah budaya politik masyarakat Melayu berubah seiring dengan isu-isu

yang muncul dalam pentadbiran kerajaan dan kematangan politik masyarakat Malaysia? Setakat 
ini, banyak kajian tentang budaya politik Melayu dilakukan. Namun, kebanyakan kajian meneliti tentang persoalan budaya politik dalam kepimpinan parti, budaya politik menerusi sesuatu pilihan raya dan hegemoni dalam budaya politik Melayu (Muhamad Nadzri \& Ghazali Mayuddin, 2008; Mohd Faidz et. al., 2011; Junaidi Awang Besar, Mohd Fuad \& Mohd Faiz, 2011; Nor Sulastry, 2014; Ilyas Abdullah, Jamaie Hamil \& Sity Daud, 2018). Kajian ini dilakukan bertujuan bagi menganalisis budaya politik masyarakat Melayu berdasarkan isu-isu politik nasional yang berlaku khususnya bermula pada era reformasi tahun 1998 sehingga tahun 2018. Analisis dilakukan berdasarkan kepada konsep budaya politik yang dikemukakan oleh Almond dan Verba (1989), iaitu budaya politik parochial, budaya politik subject dan budaya politik participant.

\section{Konsep Melayu}

Umumnya di Malaysia, masyarakat memahami konsep Melayu berdasarkan asal-usul keturunan orang yang berbangsa Melayu, berbahasa Melayu dan beragama Islam. Sacara spesifiknya, terdapat pelbagai definisi berhubung dengan konsep Melayu. Misalnya, menurut Abdul Rahman Embong (2000), terdapat tiga pendekatan konsep Melayu. Pertama, konsep Melayu yang menggunakan kesamaan bahasa dan budaya. Kedua, konsep Melayu berasaskan kepada penggunaan nama Melayu. Ketiga, konsep Melayu berdasarkan kepada Perlembagaan Persekutuan Malaysia, iaitu Melayu adalah seseorang yang beragama Islam, lazim bercakap bahasa Melayu dan menurut adat istiadat Melayu.

Manakala, menurut Haziyah Hussin (2004), konsep bangsa Melayu adalah sangat luas berdasarkan definisi yang diberikan oleh beberapa sarjana seperti Ismail Hussein, Salazar, Bellwood dan Wan Hashim. Dalam kajian beliau, hasil analisis daripada sarjana di atas menunjukkan konsep Melayu boleh dilihat berdasarkan pelbagai perspektif antaranya Melayu merupakan suku bangsa serumpun di Nusantara, perkataan Melayu dirujuk kepada Kepulauan Melayu, kelompok ras Melayu digolongkan kepada kumpulan Melayu Polinesia, Melayu dikaitkan dengan nilai tradisi berdasarkan ekonomi, politik dan budaya, serta kaum Melayu dikaitkan dengan bahasa Melayu.

Menurut Shamsul Amri Baharuddin (2020), Melayu diklafikasikan melaui takrifan 'authority defined' dan 'everyday defined'. Klafikasi melalui takrifan 'authority defined' adalah merujuk kepada kedudukan Melayu di dalam perlembagaan Malaysia (Perkara 160) manakala 'everyday defined' pula merujuk kepada Melayu berdasarkan adat resam dan budaya. Hal ini kerana, kesahihan Melayu itu sememangnya telah termaktub di dalam perlembagaan dan dalam pengamatan budaya masyarakat Melayu itu sendiri. Ini kerana masyarakat Melayu, pada asasnya, sudah ada sistem etika sendiri seperti adat resam dan istiadat, manakala, 'authority defined' Melayu bukan sahaja termaktub dalam Perkara 160 malah dalam bagahian-bahagian lain dalam perlembagaan Malaysia contoh yang boleh diambil Misalnya dalam kalangan peribumi di Sarawak. Kebanyakannya kekal berpegang dengan Undang-Undang Adat masing-masing serta mempunyai mahkamah khusus untuk itu iaitu Mahkamah Adat (atau sekarang dikenali sebagai Mahkamah Bumiputera).

Berdasarkan konsep yang dibincangkan di atas orang Melayu merujuk kepada sekumpulan masyarakat yang menggunakan nama Melayu, mengamalkan bahasa dan budaya Melayu serta diiktiraf melalui perlembagaan Malaysia. Masyarakat Melayu adalah majoriti dan paling dominan di Malaysia yang mana berdasarkan banci penduduk pada tahun 2010 jumlah etnik Melayu adalah separuh daripada jumlah penduduk Malaysia, iaitu 14,191,720 juta berbanding 28,334,135 juta penduduk Malaysia (Jabatan Perangkaan Malaysia, 2019). Jumlah tersebut sudah pasti berubah 
dan semakin bertambah seiring dengan peningkatan penduduk Malaysia yang dianggarkan berjumlah 32.4 juta orang pada tahun 2018 (Berita Harian, 2018).

\section{Budaya politik}

Budaya politik secara umum merujuk kepada sikap atau tingkah laku masyarakat secara bersama terhadap sistem politik dalam konteks sesebuah negara. Budaya politik berbeza dengan sistem politik, sistem politik adalah suatu sistem untuk menjalankan fungsi pemerintahan dalam sesebuah negara. Menurut Sumartono (2018), budaya politik ditandai dengan kesedaran politik yang sangat tinggi. Sistem politik mengandungi tiga aspek, iaitu struktur (badan perundangan, eksekutif dan birokrasi), pemerintah (monarki/demokrasi, pembuat undang-undang dan pentadbir) dan dasar awam (dasar, keputusan dan pelaksanaan) (Almond \& Verba, 1989). Manakala budaya politik adalah bagaimana penerimaan atau tindakan masyarakat terhadap sistem politik, iaitu struktur, pemerintah dan dasar awam yang dilaksanakan oleh kerajaan. Menurut Ahmad Nidzamuddin (2002), sistem politik mungkin boleh menurut aturan yang sama seperti Malaysia dan Great Britain yang mengamalkan demokrasi berparlimen, tetapi budaya politik agak sukar mempunyai persamaan kerana ia melibatkan latar belakang, latar sejarah, agama, pendidikan, struktur masyarakat dan sebagainya yang berkaitan dengan masyarakat tersebut. Kavanagh (1987) mendefinisikan budaya politik sebagai orientasi dan sikap politik yang dipengaruhi oleh tindakan politik dan ditentukan berdasarkan beberapa elemen utama seperti tradisi, peristiwa sejarah, motif, norma, perasaan dan simbol. Oleh itu, budaya politik boleh dikelaskan berdasarkan orientasi masyarakat terhadap politik secara menyeluruh.

Sementara itu, Almond dan Verba (1989) mendefinisikan budaya politik sebagai orientasi politik secara spesifik, iaitu sikap terhadap sistem politik dan aspek yang berkaitan dengannya serta sikap terhadap pemerintah dan mereka yang terlibat dengan sistem politik. Almond dan Verba mencirikan budaya politik kepada tiga jenis. Pertama, parochial politcal culture, iaitu wujud dalam kalangan masyarakat yang tidak mempunyai maklumat dan tidak ambil tahu tentang urusan politik. Mereka hanya mengutamakan urusan keluarga dan urusan peribadi sahaja. Bagi mereka urusan politik dan negara diurus oleh pihak yang bertanggungjawab. Kedua, subject political culture merujuk kepada mayarakat yang menerima maklumat dan output daripada sebelah pihak, iaitu pihak kerajaan tanpa mempersoalkan apa, bagaimana dan mengapa ia berlaku. Masyarakat memberi sepenuh kepercayaan kepada kepimpinan negara dalam urusan pentadbiran dan tidak terlibat dalam proses input. Ketiga participant political culture, iaitu masyarakat mendapat maklumat daripada pihak kerajaan dan mereka mempunyai kesedaran politik yang tinggi. Budaya politik ini menunjukkan rakyat sentiasa mengambil bahagian dalam dasar dan pemerintahan negara dan peka tentang isu-isu yang berlaku khususnya yang melibatkan hal ehwal negara dan keputusan kerajaan. Mereka terlibat dalam proses input dan output.

Budaya politik merupakan suatu persoalan yang membincangkan mengenai sikap dan orientasi psikobudaya sesebuah masyarakat terhadap politik. Asasnya ialah budaya politik merangkumi persepsi ke atas tadbir urus kerajaan, persepsi masyarakat terhadap sistem politik, persepsi terhadap kepimpinan dan pandangan-pandangan serta reaksi masyarakat terhadap unsurunsur atau hal-hal yang berkait-rapat dengan politik. Semua aspek budaya politik ini boleh berubah dari pelbagai dimensi dan pengalaman yang dilalui oleh sesebuah masyarakat (Mohd Mahadee Ismail, 2018). Budaya politik Melayu dikatakan telah memasuki tranformasi baru iaitu timbulnya beberapa ideologi dan pemikiran politik yang dikatakan boleh menggugat budaya politik yang sedia ada. Antaranya wujud aliran ideologi sosialis, komunis, keagamaan dan juga nasionalisme 
(Noor Aziera et al., 2017).

Berdasarkan definisi yang dibahaskan di atas, budaya politik dalam kajian ini merujuk kepada budaya politik orang Melayu, iaitu sikap, kepercayaan, emosi, nilai, penerimaan dan tindakan yang diambil terhadap sistem politik yang difokuskan kepada aspek pemerintahan seperti dasar negara dan keputusan kerajaan terhadap sesuatu isu. Seterusnya, kajian ini menerima pakai konsep budaya politik yang dikemukakan oleh Almond dan Verba (1989) dalam menganalisis budaya politik masyarakat Melayu di Malaysia.

\section{Sorotan karya}

Muhammad Nadzri dan Ghazali Mayudin (2008) membincangkan tentang penguasaan parti pemerintah BN selama 50 tahun dalam konteks hegemoni dan kontra hegemoni yang memungkinkan berlaku perubahan dalam PRU 2008. Menurut mereka, hegemoni adalah kaedah pendominasian kelas dominan (termasuk golongan pemerintah) ke atas massa daripada sudut minda dan fizikal dalam usaha untuk mendapatkan kepatuhan dan sokongan. Kajian mereka mendapati kejayaan BN mendominasi politik sebelum PRU ke-12 disebabkan oleh konstruksi superstruktur, iaitu institusi bukan material yang menjadikan mereka sangat hegemoni. Dalam hal ini, mereka dapat mengawal pemikiran masyarakat khasnya orang Melayu dalam pelbagai cara seperti menerusi media massa, masyarakat sivil, sistem pendidikan dan parti politik. Walau bagaimanapun, di bawah kepimpinan Abdullah Badawi hegemoni UMNO/BN mula terhakis disebabkan beberapa faktor, antaranya masalah ekonomi, peribadi Abdullah yang tidak tegas sehingga banyak pihak berani mengkritik dan mengadakan protes seperti BERSIH dan HINDRAF (Barisan Bertindak Hak Asasi Hindu) serta kemunculan media baru yang mencabar kredibiliti media massa di bawah penguasaan kerajaan. Terhakisnya hegemoni tersebut menyebabkan sokongan masyarakat kepada kerajaan dalam PRU 2008 merosot dengan teruk.

Mohd Faidz et al. (2011) mengkaji tentang budaya politik Melayu dalam UMNO. Dapatan kajian mereka menunjukkan budaya politik Melayu dalam UMNO dipelopori ideologi politik nasionalisme atau semangat kebangsaan. Ideologi kebangsaan tersebut dibahagikan kepada tiga tahap, iaitu pertama sebelum 1946. Pada tahap ini gerakan politik orang Melayu dikatakan sebagai nasionalisme haluan kiri yang dipelopori oleh Kesatuan Melayu Muda (KMM). Kedua, nasionalisme Melayu 1946 sehingga merdeka. Pada tahap ini Orang Melayu bersatu padu dan bangkit menentang penubuhan Malayan Union pada tahun 1946 dan juga menuntut kemerdekaan dari British. Senario ini juga telah membawa kepada penubuhan UMNO pada 11 Mei 1946. Ketiga, krisis UMNO 1987, iaitu wujud perpecahan dalam asas nasionalisme Melayu akibat daripada pertandingan merebut jawatan Presiden UMNO antara Dr. Mahathir dan Tengku Razaleigh Hamzah.

Perbincangan mengenai budaya politik Melayu dalam pilihan raya pula dikaji oleh Junaidi Awang Besar, Mohd Fuad dan Mohd Faidz (2011). Hasil kajian mereka menunjukkan bahawa ciri-ciri budaya politik Melayu mempengaruhi undi dalam pilihan raya kecil Hulu Selangor dan memberi kemenangan kepada BN walaupun calon yang diletakkan adalah dari kaum India, dan majoriti pengundi di Hulu Selangor adalah kaum Melayu. Ini kerana BN telah berjaya memberi keutamaan terhadap isu-isu yang berkaitan dengan ciri budaya Melayu, iaitu Raja-raja Melayu, Islam, Bahasa Melayu, ekonomi dan universal (politik baharu) di sepanjang kempen pilihan raya di adakan. Manakala Parti Keadilan Rakyat (PKR) yang meletakkan calon Melayu dan pernah 
menang dalam PRU 2008 telah tewas kerana tidak menjaga ciri budaya Melayu tersebut dalam tempoh masa berkempen.

Tulisan Noor Sulastry dan Nor Azila (2013) mengkaji tentang budaya politik Melayu yang telah mengalami perubahan daripada hegemoni kepada kontra hegemoni. Kajian mereka mendapati tragedi 13 Mei 1969 telah meningkatkan penguasaan UMNO dalam sosiopolitik Malaysia sehingga mewujudkan hegemoni politik apabila minoriti elit pemerintah mendominasi politik, ekonomi, mengawal mobiliti massa dan memberikan pengaruh terhadap media. Walau bagaimanapun mereka mendapati konsep hegemoni telah mengalami perubahan pada zaman Abdullah Badawi apabila masyarakat mula memperlihatkan tindakan kontra hegemoni, rakyat semakin berani meyuarakan pendapat secara terbuka terutama menerusi ruang siber. Kecenderungan ini juga menyaksikan kebangkitan golongan muda yang mula menuntut proses demokrasi yang lebih baik daripada pihak pemerintah dan memihak kepada perjuangan politik pembangkang.

Kajian yang dijalankan oleh Ilyas Abdullah, Jamaie Hamil \& Sity Daud (2018) menunjukan bahawa pembangunan merupakan faktor utama yang mempengaruhi pembentukan budaya politik Melayu di Terengganu sebelum dan selepas PRU ke 10. Namun begitu pasca PRU ke 10 masyarakat Melayu mula melihat bahawa pembangunan bukan lagi semata-mata mengecapi nikmat keselesaan malahan mesti turut disepadukan dengan prinsip keadilan. Pengundi cenderung untuk bertindak dengan memberikan tindakbalas yang negatif kepada kerajaan sekiranya dasar atau pembangunan yang dibawa oleh kerajaan tidak memberikan hasil atau faedah ekonomi kepada pengundi,

Kajian sarjana di atas menganalisis budaya politik Melayu melalui kajian mereka dalam pilihan raya dan analisis dalam kepimpinan parti UMNO. Kebanyakan kajian mereka mendapati budaya politik Melayu telah mengalami perubahan sama ada dalam kepimpinan parti politik UMNO mahupun berkaitan dengan perubahan budaya politik secara keseluruhan yang dinilai melalui keputusan pilihan raya.

\section{Metodologi}

Kajian ini menggunakan kaedah kualitatif. Data diperoleh melalui jurnal, buku, laporan kajian dan juga laporan agensi kerajaan. Kaedah kualitatif dipilih kerana artikel ini membincangkan tentang perubahan fenomena masyarakat terutamanya berkaitan dengan aspek budaya. Selain itu, pemerhatian juga dilakukan terhadap isu-isu politik Malaysia khususnya dalam tempoh 1998 sehingga 2019. Maklumat yang diperoleh dianalisis dengan menggunakan analisis kandungan dan dibincangkan berdasarkan tujuan kajian. Analisis tersebut dapat menghuraikan bagaimana perubahan budaya dalam masyarakat Melayu berdasarkan beberapa peristiwa yang berlaku dan dikaitkan dengan konsep budaya politik iaitu "parochial", "subject" dan "participant.

\section{Dapatan dan perbincangan kajian}

Budaya sesebuah masyarakat, termasuk budaya politik bukanlah sesuatu yang statik, tetapi berubah seiring dengan perubahan masa. Menurut Noor Sulastry (2014), budaya politik bukan sesuatu yang bersifat statik tetapi bertindak balas terhadap idea baru yang dijana dari dalam sistem ataupun diterima dari luar. Begitu juga dengan budaya politik masyarakat Melayu di Malaysia 
yang sedang mengalami transformasi mengikut peredaran zaman. Budaya politik masyarakat Melayu sebelum kedatangan penjajah di zaman Kesultanan Melaka adalah bersifat feudal, akur dan submisif yang tidak ada nilai demokrasi, kebebasan, persaingan dan sivil yang dituntut oleh kebanyakan masyarakat sekarang. Rakyat secara sukarela membenarkan setiap tindakan yang diambil oleh pemerintah (Ahmad Nizamuddin, 2002; Noor Sulastry \& Nor Azila, 2013). Jadi, ketika itu budaya politik masyarakat Melayu adalah lebih bersifat parochial, kerana masyarakat ketika itu tidak mengambil tahu urusan politik dan menyerahkan sepenuhnya hal ehwal pemerintahan kepada raja atau pemerintah tanpa persoalan dan bantahan.

\section{Budaya politik Melayu: Dari budaya politik Parochial ke budaya politik Subject}

Selepas kedatangan penjajah, budaya politik di negara-negara yang dijajah termasuk Malaysia (ketika itu Tanah Melayu) telah mengalami sedikit perubahan daripada masyarakat feudal yang tidak ada nilai demokrasi dan kebebasan kepada masyarakat yang mula menuntut kesaksamaan, keadilan dan perjuangan untuk meningkatkan mutu bangsanya. Buktinya, pada tahun 1930-an, muncul kumpulan berhaluan kiri yang dipelopori oleh KMM untuk menuntut kebebasan dan memperjuangkan semangat nasionalisme (Mohd Faidz et al., 2011). Manakala, pada tahun 1946 pula, masyarakat Melayu telah bersatu padu bangkit untuk menentang penubuhan Gagasan Malayan Union kerana ia boleh menggugat kedudukan Raja-Raja Melayu dan hak istimewa orang Melayu. Penentangan tersebut telah dilakukan dengan pelbagai cara seperti rapat umum, peranan media massa yang menyebarkan maklumat dan juga penubuhan organisasi secara rasmi, iaitu UMNO. Selepas Malayan Union dibubarkan, perjuangan orang Melayu diteruskan lagi untuk menuntut kemerdekaan daripada British.

Ringkasnya, ketika zaman penjajahan budaya politik masyarakat Melayu telah mengalami transisi, iaitu dari budaya parochial ke arah budaya politik subject. Hal ini kerana masyarakat telah mula menerima maklumat dan mula mengambil tahu apakah implikasi kepada masyarakat dan negara. Walau bagaimanapun, ia masih bersifat pasif, bersuara terhadap isu-isu tertentu sahaja dan melibatkan kumpulan tertentu sahaja, seperti tentangan terhadap penubuhan Malayan Union dan juga tuntutan kemerdekaan yang di adakan secara rundingan oleh wakil parti politik UMNO, MCA dan MIC. Seperti mana yang dinyatakan oleh Ahmad Nizamuddin (2002), di era penjajahan, nilainilai tradisional tidak semuanya pupus manakala nilai yang dibawa oleh penjajah juga tidak dapat diterapkan sepenuhnya. Ini menyebabkan ia masih berada ditahap transisi dari sifat moden tradisi kepada satu bentuk baharu.

Justeru, selepas kemerdekaan, budaya politik subject yang sedang mengalami transisi mula sinonim dengan masyarakat Malaysia amnya dan masyarakat Melayu secara khususnya. Selepas mencapai kemerdekaan masyarakat menerima maklumat dan juga output dalam bentuk pembangunan ekonomi dan juga pembangunan infrastruktur sosial. Ketika itu masyarakat secara umumnya hanya menerima maklumat dan dasar kerajaan, tanpa mempersoalkan tindakan dan keputusan kerajaan. Namun begitu, pada tahun 1970-an muncul kumpulan pelopor yang mula mempersoal dan menyatakan ketidakpuasan terhadap dasar-dasr kerajaan. Misalnya, pada tahun 1974 kumpulan mahasiswa yang diketuai oleh Anwar Ibrahim telah mengadakan demonstrasi menyalahkan dasar kerajaan terhadap isu kemiskinan petani di Baling Kedah. (Hassan Karim, 1984; Means, 1991; Brown, 2004; Saifuddin Abdullah, 2009). Kemudian pada tahun 1980-an dan 1990-an, muncul lagi beberapa golongan yang tidak berpuas hati dengan dasar dan keputusan kerajaan. Pertama, pada tahun 1984 protes telah dilakukan oleh Pertubuhan Bukan Kerajaan (NGO), iaitu Environmnetal Protection Society Malaysia (EPSM) dan Jawatankuasa Anti 
Radioaktif Perak (PARC) berhubung keputusan kerajaan membenarkan pembangunan tapak sisa buangan radioaktif oleh syarikat Asian Rare Earth (ARE). Mereka mengadakan protes dan membantah pembuangan sisa radioaktif ini kerana ia memberi kesan buruk kepada persekitaran dan juga menjejaskan kesihatan penduduk setempat (Brown, 2004).

Kedua, pada tahun 1986 terdapat protes daripada masyarakat berhubung dengan pindaan Akta Rahsia Rasmi (OSA). Tindakan kerajaan meminda OSA telah menyebabkan berlaku demonstrasi oleh lebih kurang 2000 wartawan, manakala Pertubuhan Kebangsaan Wartawan (PKW) telah mengumpul 36,000 tandatangan orang ramai yang turut membantah pindaan tersebut (Means, 1991; Brown, 2004). Mohd Faiz et al. (2011) menyatakan krisis UMNO 1987 juga telah mewujudkan perpecahan dalam asas nasionalisme Melayu. Akhir sekali, yang menjadi penanda aras kepekaan dan kebangkitan masyarakat Melayu terhadap hal ehwal politik di Malaysia ialah bantahan dan protes jalanan berhubung pemecatan Timbalan Perdana Menteri Anwar Ibrahim pada 2 September 1998. Misalnya pada 20 September 1998 Anwar Ibrahim dan penyokongnya mengadakan demonstrasi secara besar-besaran di sekitar Masjid Negara dan Dataran Merdeka dan menerima sokongan hebat daripada masyarakat Melayu, terutamanya golongan muda yang dianggarkan melebihi 30,000 orang. Semasa proses perbicaraan Anwar Ibrahim pula, iaitu antara Oktober 1998 hingga April 1999, demonstrasi diteruskan di mahkamah dan jalan sekitarnya. Seterusnya, hukuman penjara ke atas Anwar menyebabkan berlakunya beberapa siri tunjuk perasaan dan demonstrasi, iaitu pada 13 hingga 16 April 1999 dan 11, 19 dan 25 September 1999 (Saravanamutthu, 2001; Wain, 2009; Tan Lee Ooi, 2010).

Peristiwa yang dibincangkan di atas menunjukkan telah munculnya kumpulan pelopor seperti kumpulan pelajar, NGO dan golongan muda yang cuba membawa perubahan dalam budaya politik Malaysia dan Melayu khususnya, iaitu tidak hanya menerima sahaja maklumat daripada pemerintah, tetapi telah mula mempersoal dan bertindak terhadap isu-isu tertentu. Kesannya, sokongan kepada BN, terutamanya UMNO mula merosot dalam PRU ke-10 pada tahun 1999. Dalam PRU tersebut BN memenangi 148 kerusi daripada 193 kerusi yang dipertandingkan berbanding 162 kerusi yang dimenangi pada PRU 1995. Selain itu, majoriti kemenangan BN juga berkurangan di beberapa buah negeri, terutamanya Selangor dan Kuala Lumpur. Misalnya, di Shah Alam calon pemuda Keadilan yang bertanding telah berjaya mengurangkan majoriti kemenangan calon BN daripada 41,000 undi pada PRU 1995 kepada hanya 1140 undi. Di Bandar Tun Razak, aktivis sosial yang bertanding atas tiket Parti Keadilan Nasional (PKN) Chandra Muzaffar telah berjaya mengurangkan majoriti kemenangan calon BN daripada 14,735 undi pada PRU 1995 kepada hanya 1224 undi pada PRU 1999. Selain itu, dua negeri yang mempunyai majoriti penduduk Melayu, Kelantan dan Terengganu jatuh ke tangan pembangkang (Suruhanjaya Pilihan Raya, 2006a).

Ini menunjukkan budaya politik masyarakat Melayu telah mengalami satu lagi transisi, iaitu dari budaya politik subject ke budaya politik participant. Pun begitu, pada tahun 2003 setelah Dr. Mahathir meletakkan jawatan dan diganti dengan Abdullah Badawi, masyarakat Melayu mula lupa isu-isu yang berlaku dan terus memberi sokongan kepada kerajaan BN pimpinan Abdullah Badawi, yang menjanjikan perubahan yang lebih baik dari segi integriti dan demokrasi. Buktinya, sokongan kepada kerajaan UMNO/BN yang merosot pada PRU 1999 kembali melonjak dalam PRU 2004. Daripada 219 kerusi Parlimen yang dipertandingkan, BN berjaya mendapat 199 kerusi (90.9 peratus). UMNO juga telah menunjukkan prestasi yang baik dengan memenangi 109 kerusi atau 92 peratus daripada kerusi yang ditandinginya berbanding dengan hanya 72 kerusi parlimen pada tahun 1999 (Suruhanjaya Pilihan Raya, 2006b). Namun, dalam fasa kedua pimpinan 
Abdullah, iaitu pada tahun 2007 muncul protes dan bantahan daripada masyarakat. Sejak daripada itu, ia telah mengubah budaya politik masyarakat Melayu ke satu tahap lagi.

\section{Budaya politik Melayu: dari budaya politik Subject ke budaya politik Participant}

Fasa kedua pentadbiran Abdullah Badawi adalah selepas PRU 2004 sehingga Mac 2009. Dalam tempoh selepas PRU 2004, banyak isu-isu yang berlaku membabitkan pentadbiran Abdullah Badawi, antaranya beliau tidak menunaikan janji PRU 2004 berkaitan dengan pentadbiran yang lebih baik dan integriti dalam pentadbiran, campur tangan keluarga dalam pentadbiran dan juga isu-isu ekonomi yang tidak dapat ditangani dengan baik (Zawiyah Mohd Zain \& Mohammad Agus, 2015). Akibatnya, berlaku ketidakpuasan hati dalam kalangan masyarakat, sehingga terdapat beberapa protes yang berlaku. Dua protes yang besar ialah oleh Bersih dan juga Hindraf. Selain itu, terdapat juga beberapa krtikan yang dilakukan menerusi media sosial, antaranya oleh Dr. Mahathir menerusi 'blog chedet', oleh bekas ahli parlimen dan bekas wartawan. Protes dan kritikan tersebut telah memberi kesan kepada sokongan masyarakat terhadap kerajaan dalam PRU 2008. Keputusan PRU tersebut menunjukkan sokongan kepada BN kembali merosot, BN gagal mendapat kemenangan majoriti dua pertiga di Dewan Rakyat dan tewas lima negeri kepada pakatan pembangkang Pakatan Rakyat. Tindak balas masyarakat terhadap isu-isu politik di fasa kedua Abdullah menunjukkan masyarakat kuhususnya orang Melayu telah mula menonjolkan budaya politik participant, yang mana mereka mula mempersoalkan tindakan kerajaan dan aktif mengambil bahagian dalam politik. Hal ini selari dengan kajian Sulastry dan Nor Azila (2013), yang mana menurut mereka pada zaman Abdullah Badawi rakyat mula meyuarakan pandangan secara terbuka dan golongan muda mula bangkit memperjuangkan demokrasi yang lebih baik.

Selepas kemerosotan sokongan kepada BN dalam PRU 2008, Abdullah Badawi meletak jawatan dan diambil alih oleh Najib Razak pada April 2009. Pada era Najib Razak, beliau berusaha untuk membuat perubahan menerusi program tarnsformasi kerajaan, supaya masyarakat yang menolak BN dalam PRU 2008 kembali semula memberi sokongan. Namun, begitu tindak balas masyarakat adalah sebaliknya, yang mana masyarakat khususnya orang Melayu semakin menjarakkan diri daripada UMNO/BN. Ini boleh dilihat berdasarkan isu-isu politik yang berlaku di sepanjang pentadbiran Najib Razak. Pada fasa pertama pentadbiran Najib, terdapat beberapa isu yang berlaku. Antaranya pertama, pada awal pemerintahan beliau, iaitu pada tahun 2009 kerajaan mengumumkan untuk mengkaji semula Akta Keselamatan dalam Negeri (ISA). Namun, terdapat tuntutan daripada NGO supaya kerajaan menghapuskan ISA bukan mengkaji. Tuntutan dilakukan melalui protes gerakan mansuh ISA (GMI) pada April 2009 dan Mac 2011.

Kedua, pada Disember 2009, beberapa kumpulan NGO dan parti pembangkang mengadakan demonstrasi membantah perancangan kerajaan untuk memperkenalkan Cukai Barangan dan Perkhidmatan (GST) bermula pada tahun 2012. Misalnya sempena Hari Buruh pada tahun 2010, kira-kira 500 orang dari kumpulan NGO yang diketuai oleh S. Aruchelvan dan Dr. Nasir Hashim dari Parti Sosialis Malaysia (PSM) berkumpul di luar bangunan Majlis Peguam Malaysia bertujuan untuk membaca Deklarasi Hari Buruh dan juga membantah pelaksanaan GST. Hasil bantahan rakyat menyebabkan kerajaan mengumumkan untuk menangguhkan dahulu pelaksanaan GST tersebut.

Ketiga, bantahan terhadap Akta Perhimpunan Aman 2012 dan Akta Kesalahan Keselamatan (Langkah-Langkah Khas) 2012. Oleh itu, rakyat telah melahirkan bangkangan terhadap kerajaan. Misalnya, semasa rang undang-undang Akta Perhimpunan Aman dibahaskan di Parlimen, beberapa kumpulan telah menyatakan bantahan dengan cara menganjurkan demonstrasi, antaranya Majlis Peguam dengan kempen walk for justice pada 29 November 2011. 
Keempat, keputusan kerajaan memperkenalkan novel Interlok sebagai teks wajib komponen sastera subjek Bahasa Melayu kepada pelajar tingkatan lima di sekolah menengah bermula pada tahun 2011 juga turut mendapat bantahan khususnya daripada kaum India kerana penggunaan perkataan paria dalam novel tersebut menghina kaum mereka. Hasilnya kerajaan telah mengambil tindakan dan meminda beberapa bahagian dalam novel tersebut sebelum ia dijadikan bahan bacaan di sekolah. Tindakan pindaan novel ini telah mendapat bantahan daripada beberapa pihak, antaranya Gabungan Penulis Nasional (Gapena), Persatuan Penulis Nasional Malaysia (PENA) dan Dewan Bahasa dan Pustaka (DBP).

Kelima, perhimpunan Bersih pada 9 Julai 2011 yang mahukan kerajaan melakukan penambahbaikan dalam sistem pilihan raya di Malaysia supaya lebih adil dan telus. Perhimpunan ini melibatkan pelbagai golongan seperti parti pembangkang, NGO, aktivis masyarakat dan mahasiswa yang terdiri daripada pelbagai kaum dan peringkat umur yang datang dari seluruh negara untuk memberi sokongan, biarpun dihalang oleh pihak polis. Sebagai tindak balas kepada perhimpunan ini kumpulan NGO pro BN, iaitu PERKASA dan Patriot yang juga disertai Ketua Pemuda UMNO Khairy Jamaluddin turut berhimpun pada hari yang sama. Bersih telah mengadakan satu lagi perhimpunan pada 28 April 2012, iaitu BERSIH 3. BERSIH 3 merupakan demonstrasi terbesar selepas reformasi 1998, yang dianggarkan mendapat sambutan 100,000 orang (Welsh, 2012). BERSIH 3 ini mendapat sambutan ramai kerana rakyat keluar berhimpun atas tiket Akta Perhimpunan Aman 2012. Pun begitu, akta tersebut adalah satu lagi tindakan kerajaan menghalang kebebasan rakyat. Ini kerana walaupun menurut akta tersebut rakyat berhak berhimpun, tetapi ia tetap memberi kuasa kepada pihak polis untuk mengambil langkah-langkah perlu mengawal mereka yang berhimpun. Jadi, pada perhimpunan BERSIH 3.0, pihak polis menggunakan kuasa mereka dan menetapkan syarat tertentu yang tidak dipersetujui oleh kumpulan BERSIH.

Selain itu, terdapat juga bantahan daripada penggiat seni dengan cara yang tersendiri. Misalnya oleh kartunis Zunar dan sasterawan negara A. Samad Said. Zunar telah mengeluarkan majalah jenaka alternatif yang diberi nama Gedung Kartun. Edisi pertama majalah tersebut dikeluarkan pada September 2009. Dalam majalah ini, selain memuatkan lukisan kartun yang berteraskan isu-isu semasa ia turut memaparkan artikel berbentuk satira politik yang melibatkan beberapa penulis kreatif seperti Hishamuddin Rais, Pyanhabib, A. Samad Said dan Rahmat Haron. Dalam edisi pertama tersebut, pelbagai isu semasa telah disentuh antaranya, kenaikan kadar tol lebuh raya, isu pengajaran dan pembelajaran sains dan matematik dalam bahasa Inggeris (PPSMI) dan ISA. Selain itu, Zunar juga turut menyumbangkan karya kartunnya kepada Malaysiakini bertajuk 'Kartunkini' untuk menunjukkan bantahan atau sindiran beliau terhadap beberapa keputusan kerajaan. Ringkasnya, karya kartun beliau merangkumi pelbagai isu seperti sistem kehakiman di Malaysia, hak asasi, rasuah, politik wang, kebebasan bersuara, pendidikan, agama dan sosial.

Manakala, bagi sasterawan negara A. Samad Said, beliau telah menunjukkan sokongan kepada BERSIH 2.0 yang berhimpun pada Julai 2011. Beliau telah menulis puisi yang memberi sokongan kepada BERSIH, bertajuk 'Unggun BERSIH' dan 'Peludah Warna'. Antara lain, keduadua puisi tersebut menggambarkan bagaimana demokrasi Malaysia yang telah mati cuba dihidupkan semula oleh kumpulan prodemokrasi dan aktivis sosial. Akibatnya, pihak polis telah memanggil A. Samad Said pada 27 Jun 2011 untuk mengambil keterangan dan beliau disiasat di bawah Akta Hasutan dan juga Akta Polis berikutan tindakan beliau membacakan puisi tersebut di majlis pelancaran BERSIH 2.0 (Malaysiakini, 2011). 
Perbincangan di atas menunjukkan isu-isu yang melibatkan ketidakpuasan terhadap sistem politik atau dasar kerajaan telah mendapat perhatian daripada masyarakat dengan cara mengadakan bantahan dalam pelbagai bentuk termasuklah oleh pengiat seni. Hal ini telah memberi kesan kepada PRU ke-13. Keputusan PRU ke-13 yang diumumkan pada 6 Mei 2013 menunjukkan pencapaian BN lebih teruk daripada PRU 2008. Ini kerana BN gagal mendapat majoriti dua pertiga bagi kerusi Dewan Rakyat dan hanya menang 133 kerusi daripada 222 kerusi parlimen, iaitu kurang lapan kerusi berbanding PRU 2008 (Suruhanjaya Pilihan Raya, 2014). Manakala, Pakatan Rakyat pula mendapat 89 kerusi. Hal ini disumbangkan oleh budaya politik Melayu yang mana mereka telah bergiat aktif dan menunjukkan nilai, dan tindakan dalam hal ehwal politik sejak daripada tahun 2007 sehingga pada tahun 2013 di bawah pentadbiran Najib Razak.

Selepas PRU 13, BN dan Najib Razak sendiri terus diselubungi dengan pelbagai isu antaranya isu berkaitan gaya hidup mewah keluarga Najib Razak, isu 1Malaysia Development Berhad (1MDB), wang derma 2.6 bilion, penyelewengan dana kerajaan, kenaikan harga barangan dan sebagainya. Hal ini menyebabkan persepsi negatif terhadap kerajaan dan tindak balas masyarakat berterusan berlaku melalui bantahan. Antaranya pertama, pelaksanaan GST pada tahun 2015. Pelaksanaan GST telah menimbulkan kemarahan rakyat kerana berlaku kenaikan harga barangan dan peningkatan kos sara hidup. Oleh itu, himpunan untuk membantah GST telah diadakan. Misalnya pada Jun 2016 bantahan diadakan di sekitar Kuala Lumpur yang dianjurkan oleh parti pembangkang, iaitu Parti Amanah Negara (PAN), Parti Keadilan Rakyat (PKR) dan Democratic Action Party (DAP).

Kedua, isu salah guna kuasa dalam kes 1MDB. Pada tahun 2015 terdapat tuduhan bahawa Najib Razak terlibat dengan skandal 1MDB, iaitu 2.6 bilion wang daripada 1MDB dimasukkan dalam akaun beliau (Saravanamuttu, 2016; Wright \& Hope, 2018). Biarpun, kerajaan menafikan salah guna kuasa dalam isu ini tetapi rakyat tidak percaya dan mereka mengadakan bantahan. Misalnya, pada Ogos 2015 terdapat sekumpulan aktivis pelajar universiti yang berkampung di luar Parlimen yang menggesa Najib Razak meletak jawatan kerana mendakwa beliau mempunyai kaitan dengan skandal 1MDB dan wang 2.6 bilion. Selain itu, pada Oktober 2017, terdapat perhimpunan yang dinamakan "sayangi Malaysia hapuskan kleptokrasi". Himpunan tersebut membabitkan parti politik pembangkang dan juga NGO yang membantah salah guna kuasa berkaitan 1MDB dan lain-lain kes salah guna kuasa dalam pentadbiran kerajaan BN.

Ketiga, isu penyelewengan dana dalam pentadbiran kerajaan. Misalnya, penyelewengan dana sebanyak RM107 juta melibatkan Kementerian Belia dan Sukan dan penyelewengan dana Kementerian Luar Bandar dan Wilayah sebanyak 1.5 bilion (Malaysiakini, 2016; Berita Harian 2017). Akhir sekali, sekatan kebebasan bersuara, kerajaan telah menguatkuasa Akta Berita Palsu pada tahun 2018. Penguatkuasaan akta tersebut mendapat bantahan, terutamanya oleh pihak pembangkang. Mereka mendakwa bahawa akta tersebut digubal bertujuan bagi menyekat kebebasan rakyat untuk bersuara, terutamanya menyekat tindakan rakyat daripada mengkrtik kerajaan menjelang PRU ke-14.

Kesan daripada isu-isu tersebut telah menyebabkan masyarakat mempunyai tahap kesedaran yang tinggi, berani menyatakan pendirian dan mengadakan bantahan serta telah bertindak untuk tidak menyokong kerajaan BN dalam PRU ke-14. Kajian yang dilakukan oleh Ilyas Abdullah, Jamaie Hamil \& Sity Daud (2018) menunjukkan bahawa pembangunan dan keselesaan semata-mata tidak dapat menarik sokongan rakyat tetapi rakyat sekarang lebih mementingkan keadilan dan faedah daripada dasar yang dibentuk oleh kerajaan.

Akibatnya dalam PRU ke-14 BN tewas kepada pakatan pembangkang Pakatan Harapan (PH) yang bekerjasama dengan Parti Warisan Sabah (WARISAN). Pada PRU tersebut, Pakatan 
Harapan (PH) dan WARISAN telah mendapat kemenangan majoriti mudah dengan memperolehi 121 kerusi (PKR: 49, DAP: 42, Parti Pribumi Bersatu Malaysia (BERSATU): 12, Parti Amanah Negara (AMANAH): 10 dan WARISAN: 8) berbanding dengan BN hanya mendapat 79 kerusi. Bagi kerusi Dewan Undangan Negeri (DUN) pula BN hanya menang di negeri Perlis dan Pahang pada PRU tersebut. BN mendapat sebanyak 166 kerusi DUN daripada 505 kerusi yang dipertandingkan. Manakala, Pakatan Harapan (PH) dan WARISAN mendapat sebanyak 247 kerusi DUN (Suruhanjaya Pilihan Raya, 2018).

Kemenangan Pakatan Harapan telah membawa Malaysia kepada era Malaysia Baharu. Malaysia Baharu bermaksud kerajaan baharu iaitu Pakatan Harapan yang berjanji membawa pentadbiran Malaysia ke arah pentadbiran yang berbeza dengan kerajaan BN, iaitu mengutamakan ketelusan, adil, terbuka, menentang rasuah, menentang penyalahgunaan kuasa, mempunyai kebebasan media dan mereformasikan semula beberapa institusi pentadbiran. Namun, setelah PH berkuasa timbul persepsi yang mengatakan bahawa PH didominasi oleh parti DAP dan cuba mengenepikan hak-hak orang Melayu. Hal ini menyebabkan ketidakpuasan hati orang Melayu termasuklah mereka yang mengundi PH sebelum ini. Misalnya, orang Melayu tidak berpuas hati dengan kerajaan PH yang dikatakan menyokong untuk meratifikasikan ICERD. Oleh itu, pada Disember 2018, masyarakat Melayu mengadakan protes menuntut supaya kerajaan PH tidak meratifikasikan ICERD. Selain itu, terdapat juga isu-isu lain yang menimbulkan ketidakpuasan hati masyarakat Melayu terhadap pemerintah $\mathrm{PH}$, antaranya seperti kenyataan akhbar dalam Bahasa Cina, isu papan tanda dalam Bahasa Cina dan cara PH menangani isu perkauman di Malaysia. Dapatan kajian yang dilakukan oleh firma penyelidik bebas, iaitu Ilham Centre dan Penang Institute pada akhir tahun 2018 menunjukkan 60 peratus responden yang terdiri daripada orang Melayu tidak berpuas hati dengan prestasi pemerintahan PH. Ini menunjukkan bahawa orang Melayu percaya tentang persepsi yang mengatakan orang bukan Islam menguasai kerajaan PH dan DAP membuat keputusan di Putrajaya (Nur Farhana Abdul Manan, 2019). Persepsi yang timbul ditambah pula dengan pergolakan dalaman parti-parti komponan $\mathrm{PH}$ akhirnya telah membawa kepada kejatuhan PH apabila Tun Mahathir meletak jawatan pada 24 Februari 2020 disebabkan kehilangan sokongan majoriti. PH yang mendapat kuasa pada 9 Mei 2018 hanya sempat memerintah selama 18 bulan sahaja.

Ringkasnya, perbincangan di atas mendapati sejak tahun 2007 masyarakat Melayu telah berterusan menunjukkan nilai, sikap dan tindakan yang sinonim dengan budaya politik participant, mereka telah aktif menyuarakan pandangan dan juga dalam tindakan membantah dasar dan keputusan kerajaan yang memberi kesan negatif kepada masyarakat. Nilai dan tindakan tersebut berterusan sehingga pada tahun 2018, akhirnya membawa kepada sejarah politik baharu di Malaysia apabila parti BN tewas buat pertama kalinya dalam pertarungan PRU. Bahkan di era Malaysia baharu, di bawah kepimpinan kearajaan Pakatan Harapan juga dapat dilihat masyarakat Melayu bertindak balas terhadap sesuatu isu yang mereka tidak bersetuju. Ini menunjukkan bermula tahun 2008 masyarakat Melayu telah mempratikkan nilai budaya politik participant.

\section{Kesimpulan}

Budaya politik adalah sesuatu nilai, pandangan dan tindakan terhadap sistem politik dan pemerintahan dalam sesebuah negara. Di Malaysia, budaya politik masyarakat Melayu adalah paling dominan kerana orang Melayu merupakan majoriti penduduk. Budaya politik bukanlah sesuatu yang statik tetapi ia berubah dari semasa ke semasa, begitu juga budaya politik masyarakat 
Melayu. Hasil analisis menunjukkan selepas kemerdekaan negara budaya politik masyarakat Melayu adalah sinonim dengan budaya subject. Pun begitu, dengan kemunculan kumpulan pelopor pelajar dan NGO yang mengadakan bantahan dan protes pada tahun 1970-an, 1980-an dan 1998, budaya politik masyarakat Melayu telah mengalami transisi ke arah budaya politik participant. Peristiwa pemecatan Timbalan Perdana Menteri Anwar Ibrahim merupakan titik tolak kepada perubahan nilai politik masyarakat Melayu, yang mana mereka mula mempersoalkan apa yang berlaku dan telah menunjukkan minat untuk terlibat aktif dalam aktiviti politik. Hal ini telah membawa mereka terlibat dengan demonstrasi jalanan di era reformasi.

Seterusnya di fasa kedua era Abdullah Badawi khususnya pada tahun 2007, muncul beberapa protes yang mempersoalkan tindakan kerajaan, dan seterusnya membawa kepada dua protes besar, iaitu Bersih dan Hindraf. Akibat daripada protes tersebut berlaku penurunan sokongan kepada kerajaan BN dalam PRU 2008. Hal ini telah menjadi asas perubahan budaya politik masyarakat Melayu kepada satu lagi tahap budaya politik yang dibincangkan oleh Almond dan Verba (1989), iaitu budaya politik participant. Sejak PRU 2008, masyarakat Melayu telah aktif mengambil bahagian dalam politik, khususnya tindak balas mereka terhadap isu-isu atau keputusan kerajaan di era Najib Razak. Perubahan nilai politik masyarakat Melayu tersebut telah memberi kesan yang besar kepada keputusan PRU di era Najib Razak, khususnya dalam PRU ke14. Ini kerana dalam PRU ke-14 UMNO/BN yang telah 60 tahun memerintah Malaysia telah tewas kepada pakatan pembangkang Pakatan Harapan. Ini menunjukkan perubahan budaya politik sesbuah masyarakat boleh memberi kesan kepada pemerintahan kerajaan sehingga membawa kepada pertukaran kerajaan. Hasil penulisan ini dapat memberi sumbangan dalam bidang politik dengan memberikan gambaran tentang perubahan politik khususnya perubahan aspek budaya dalam masyarakat Melayu sejak kemerdekaan sehingga ke hari ini. Kajian ini juga penting ke arah keseimbangan dan kematangan proses demokrasi di Malaysia.

\section{Rujukan}

Abdul Rahman Embong. (2000). Negara bangsa proses dan perbahasan. Bangi: Penerbit Universiti Kebangsaan Malaysia.

Ahmad Nizamuddin Sulaiman. (2002). Budaya politik dalam masyarakat majmuk di Malaysia. Dalam Abdul Monir Yaacob dan Suzalie Mohamad (pnyt). Etika dan budaya berpolitik dari perspektif Islam. Kuala Lumpur: Institut Kefahaman Islam Malaysia.

Almond, G.A. dan Verba, S. (1989). The civic culture: Political attitudes and democracy in five nations. Newbury Park, Carlifornia: Sage.

Berita Harian. (2017). Kes seleweng dana awam: 2 bekas pegawai Shafie dibebas. Berita Harian (24 Oktober). Diakses di laman web, https:/www.bharian.com.my/berita/kes/2017/10/341245/kes-seleweng-danaawam-2-bekas-pegawai shafie-dibebas

Berita Harian. (2018). Penduduk Malaysia 32.4 juta. Berita Harian (1 Ogos). Diakses di laman web, https://www.bharian.com.my/berita/nasional/2018/08/456681/penduduk-malaysia324-juta

Brown, G. K. (2004). Civil society and social movements in an ethnically divided society: The case of Malaysia, 1981-2001. Tesis PhD yang diterbitkan. University of Nottingham.

Hassan Karim. (1984). The student movement in Malaysia, 1967-74. Dalam Hassan Karim dan Siti Noor (pnyt.). With people: The Malaysian student movement, 1967-74. Petaling Jaya: Institute of Social Analysis. 
Haziyah Hussin. (2004). Orang Melayu Kelantan dari sudut budaya dan perspektif sejarah lampau. Jebat, 31, 15-38.

Ilyas Abdullah, Jamaie Hamil \& Sity Daud. (2018). Politik baru pasca PRU Ke-10: Analisis terhadap transformasi budaya politik Melayu Terengganu. Sains Insani, 03(1), 67-74.

Jabatan Perangkaan Malaysia. (2019). Banci Penduduk Malaysia 2010. Diakses di laman web, https://www.statistics.gov.my/censusatlas/images/ReligionEN.pdf

Junaidi Awang Besar, Mohd Fuad Mat Jali \& Mohd Faidz Mohd Zain. (2011). Kajian budaya politik Melayu dalam pilihan raya kecil Hulu Selangor, Selangor. Jurnal Melayu, 8, 153172.

Kavanangh, D. (1987). Budaya Politik. (Terj.) Samaruddin Md Rejab. Kuala Lumpur: Dewan Bahasa dan Pustaka.

Malaysiakini. (2011). BERSIH 2.0: A Samad Said, Ambiga dan Ibrahim disiasat. Malaysiakini (27 Jun). Diakses di laman web, https://www.malaysiakini.com/news/168109

Malaysiakini. (2016). Seleweng dana KBS, dua lagi ditahan SPRM. Malaysiakini (24 Mac). Diakses di laman web, https://www.malaysiakini.com/news/335022

Means, G. P. (1991). Malaysian politics: the second generation. Singapore: Oxford University Press.

Mohd Faidz Mohd Zain, Jamaie Jamil, Mohd Rizal Mohd Yaakob \& Mohamad Rodzi Abd Razak. (2011). Pengaruh nasionalisme Melayu mewarnai budaya politik Melayu dalam UMNO. Jurnal Melayu, 7, 193-216.

Mohd Mahadee Ismail (2018). Budaya Politik Kontemporari Masyarakat Melayu di Semenanjung Malaysia: Satu Penilaian Kritis. Jurnal Sultan Alauddin Sulaiman Shah, Special issue (2018).

Muhammad Nadzri Mohamed Noor \& Ghazali Mayudin (2008). Hegemoni dan kontra hegemoni: Memahami perubahan pilihan raya umum ke-12. Jebat, 35, 33-48.

Noor Aziera Mohamad Rohana, Mohd Faizal P. Rameli, Rawi Nordin, \& Siti Nurul Izza Hashim. (2017). Kepelbagaian dan kesepaduan etnik di Malaysia menurut Islam. Sains Insani, 02(02), 88-97.

Noor Sulastry Yurni Ahmad \& Nor Azila Mohd Azidin. (2013). Transisi kontra hegemoni dalam budaya politik Malaysia. Melayu, 120-137.

Noor Sulastry Yurni Ahmad. (2014). Hegemoni budaya politik Melayu. Bangi: Penerbit Universiti Kebangsaan Malaysia.

Nur Farhana Abdul Manan. (2019). Kajian Ilham Centre "loceng amaran" buat PH. Sinar Harian (21 Januari). Diakses di laman web https://www.sinarharian.com.my/article/10697

Saifuddin Abdullah. (2009). Kalau saya mahasisiwa. Diakses di laman web, www.saifuddinabdullah.com.my/ebook/kalau_saya_mahasiswa.pdf

Saravanamuttu, J. (2001). Malaysia civil society-awakenings? Dalam Maznah Mohamad \& Wong, Soak Koon (pnyt.). Risking Malaysia: culture, politics and identity, (hlm. 93-111). Bangi: Penerbit Universiti Kebangsaan Malaysia.

Saravanamuttu, J. (2016). Power sharing in a divided nation: Mediated communalism and new politics in six decades of Malaysia's elections. Singapore: ISEAS Publishing.

Shamsul Amri Baharuddin. (2020). Melayu, Malaysia Dan Kerumitannya: Wawancara Bersama Shamsul Amri Baharuddin. Naratif Malaysia, 6 Jun 2020

Sumartono. (2018). Budaya Politik Dalam Masyarakat Pragmatis. Jurnal Lugas. Vol. 2, No. 1, Juni 2018, pp. 20 - 26. http://ojs.stiami.ac.id 
Suruhanjaya Pilihan Raya Malaysia. (2018). Keputusan pilihan raya 2018. Diakses di laman web, http//:www.spr.gov.my

Suruhanjaya Pilihan Raya. (2006a). Laporan pilihan raya umum Malaysia 1999. Kuala Lumpur: Percetakan Nasional Malaysia.

Suruhanjaya Pilihan Raya. (2006b). Laporan pilihan raya umum Malaysia 2004. Kuala Lumpur: Percetakan Nasional Malaysia.

Suruhanjaya Pilihan Raya. (2008). Laporan pilihan raya umum ke-12, 2008. Kuala Lumpur: Percetakan Nasional Malaysia.

Suruhanjaya Pilihan Raya. (2014). Edisi Khas Pilihan Raya 2013. Kuala Lumpur: Percetakan Nasional Malaysia berhad.

Tan, Lee Ooi. (2010). Dinamik ruang siber dalam gerakan reformasi di Malaysia. Bangi: Penerbit Universiti Kebangsaan Malaysia.

Wain, B. (2009). Malaysian maverick: Mahathir Mohamad in turbulent times. London: Palgrave Macmillan.

Welsh, B. (2012). Road to Malaysia's day of destiny. Malaysiakini 6 May 1-5. Diakses di laman web, http://blog.limkitsiang.com/

Wright, T. \& Hope, B. (2018). Billion dollar whale. New York: Hachette Book Group.

Zawiyah Mohd Zain \& Mohammad Agus Yusoff. (2015). The emergence of civil disobedience: A comparison during Dr. Mahathir and Abdullah Badawi's era. Mediterranean Journal of Social Sciences, 6(1), 279-285. 